\title{
Efficacy of Vortioxetine on Anhedonia: Results from a Pooled Analysis of Short-Term Studies in Patients with Major Depressive Disorder
}

This article was published in the following Dove Press journal: Neuropsychiatric Disease and Treatment

Roger S Mclntyre iD '

Henrik Loft ${ }^{2}$

Michael Cronquist Christensen (iD) ${ }^{3}$

'Mood Disorders Psychopharmacology Unit, University Health Network, University of Toronto, Toronto, ON, Canada; ${ }^{2}$ Department of Biostatistics and Programming, $H$. Lundbeck A/S, Valby, Denmark; ${ }^{3}$ Department of Psychiatry Products, H. Lundbeck A/S, Valby, Denmark
Correspondence: Michael Cronquist Christensen

H. Lundbeck A/S, Ottiliavej 9, 2500 Valby, Denmark

Tel +4530835168

Email MCRC@lundbeck.com
Purpose: Anhedonia is a core symptom of major depressive disorder (MDD), which has important functional consequences for the patient. This post hoc analysis investigated the relationship between anhedonia and functioning in patients with MDD treated with vortioxetine.

Patients and Methods: We conducted a pooled analysis of all 11 short-term, double-blind, randomized, placebo-controlled studies of vortioxetine (fixed dose, 5-20 mg/day) in patients with MDD which included Montgomery-Åsberg Depression Rating Scale (MADRS) and Sheehan Disability Scale (SDS) assessments. A short-term, randomized, active-controlled trial of flexible-dose treatment with vortioxetine (10-20 mg/day) versus agomelatine ( $25-50 \mathrm{mg} /$ day) was also analyzed. Mean changes from baseline to study endpoint in MADRS total, MADRS anhedonia subscale, SDS total, and SDS social-functioning scores were analyzed by a mixed model for repeated measures. The relationship between treatment effects on anhedonia and functioning was investigated using path analysis.

Results: A total of 4988 patients with MDD were included in the placebo-controlled studies and 495 in the active-comparator study. Significant dose-dependent improvements in overall depressive symptoms, anhedonia, and measures of functioning were seen in vortioxetinetreated patients compared with those who received placebo or agomelatine. Results of the path analysis for the placebo-controlled studies suggested that the effect on functioning was mostly driven by the effect of treatment on MADRS anhedonia factors.

Conclusion: Vortioxetine showed significant short-term efficacy against anhedonia in this large population of patients with MDD. In the placebo-controlled studies, improvements in functioning associated with vortioxetine appeared to be mostly driven by the effect of treatment on MADRS anhedonia factors.

Keywords: anhedonia, functioning, major depressive disorder, vortioxetine

\section{Introduction}

Anhedonia - defined as loss of interest and lack of reactivity to pleasurable stimuli - is a multidimensional domain that includes motivational and consummatory aspects of reward anticipation, experience, and evaluation. ${ }^{1,2}$ Anhedonia is a common symptom of major depressive disorder (MDD) and many other psychiatric disorders, ${ }^{3}$ particularly schizophrenia, ${ }^{4}$ and is a key diagnostic criterion for a major depressive episode. $^{3}$ It is reported in up to $75 \%$ of patients with MDD, ${ }^{5,6}$ and is a common residual symptom in patients with MDD receiving antidepressant treatment. ${ }^{7}$ Indeed, it has been suggested that experiencing a restricted range of 
emotions may be an adverse effect associated with some classes of antidepressants. ${ }^{8}$ For example, up to $60 \%$ of patients with MDD treated with selective serotonin reuptake inhibitors (SSRIs) or serotonin-noradrenaline reuptake inhibitors (SNRIs) report some degree of emotional numbness or blunting. ${ }^{8-11}$

Presence of anhedonia has been shown to be significantly associated with MDD symptomatology, with higher rates of social withdrawal, social impairment, reactivity of mood, brooding about past events, and diurnal mood variation observed in patients reporting anhedonia compared with those who do not. ${ }^{12}$ From the patient's perspective, anhedonia is also identified as having a major negative impact on self-reported psychosocial functioning. ${ }^{13}$ Anhedonia appears to be a predictor of non-response to many antidepressants. ${ }^{14-18}$ There is also evidence to suggest a complex relationship between anhedonia and suicidality in patients with MDD. ${ }^{19-22}$

There is currently no specific pharmacological approach recommended for the treatment of anhedonia in patients with MDD. The neurobiology of anhedonia implicates distinct neurochemical systems and brain regions and circuits, including disturbances of central dopaminergic mesolimbic and mesocortical reward circuit pathways that involve brain regions such as the ventral tegmental area, ventral striatum, nucleus accumbens, orbitofrontal cortex, anterior cingulate cortex, and prefrontal cortex. ${ }^{23,24}$ Although there is evidence that serotonergic pathways have a role in the development of anhedonia in $\mathrm{MDD},{ }^{24}$ disappointing treatment outcomes with SSRIs suggest that other neurotransmitters might play a more prominent role. ${ }^{18}$ In particular, dopaminergic transmission has been shown to be key to the modulation of motivation and "reward processing" in humans. ${ }^{25,26}$ However, there is also evidence for the involvement of glutaminergic and opioid systems, ${ }^{24}$ and inflammatory cytokines may also play a role. ${ }^{23}$

Vortioxetine is a multimodal antidepressant, with a unique pharmacologic profile. ${ }^{27-29}$ Vortioxetine acts as an inhibitor of the serotonin (5-HT) transporter as well as modulating the activity of multiple 5-HT receptor subtypes, thus directly and indirectly influencing the activity of several neurotransmitter systems relevant to the neurobiology of anhedonia including serotonergic, noradrenergic, dopaminergic, cholinergic, and histaminergic systems. ${ }^{27-29}$ Preclinical findings (eg sucrose preference tests and hippocampal brain-derived neurotrophic factor levels) suggest that vortioxetine engages neurotransmitter systems relevant to reward, motivation, and pleasure. ${ }^{30}$
Phenotypic and neurobiologic overlap exists between anhedonia and general cognitive processes. ${ }^{31}$ For example, activation of the innate immunoinflammatory system in patients with MDD is highly associated with both impaired cognitive performance and measures of anhedonia. ${ }^{32,33}$ The neurochemical and neurocircuit effects of vortioxetine, combined with its demonstrated pro-cognitive effects, ${ }^{34}$ suggest it may also have beneficial effects on anhedonia in patients with MDD.

Significant improvement in anhedonia, as measured by both the Snaith-Hamilton Pleasure Scale (SHAPS) total score and the Montgomery-Åsberg Depression Rating Scale (MADRS) anhedonia subscale score, has been reported in patients with MDD treated with vortioxetine. ${ }^{6}$ Of note, the observed improvement in anhedonia was found to be statistically significantly correlated with improvement in patient functioning. The present analysis was undertaken to replicate and extend these preliminary findings in a larger patient population.

\section{Patients and Methods}

\section{Study Population}

The analyses included all 11 short-term (6 or 8 weeks), double-blind, randomized, fixed-dose, placebo-controlled studies conducted by Takeda/Lundbeck that investigated the efficacy of vortioxetine $(5-20 \mathrm{mg} /$ day $)$ for the treatment of MDD and which included MADRS and Sheehan Disability Scale (SDS) assessments. All studies were conducted in adult patients with a primary diagnosis of singleepisode or recurrent MDD according to Diagnostic and Statistical Manual of Mental Disorders (4th Edition, Text Revision) criteria. ${ }^{35}$ Additional eligibility criteria of individual studies are summarized in Table 1.

Data were also analyzed from a short-term (12-week), randomized, active-controlled trial of flexible-dose treatment with vortioxetine (10-20 mg/day) compared with agomelatine $(25-50 \mathrm{mg} /$ day) in patients with MDD who had an inadequate response to SSRI/SNRI monotherapy (NCT01488071). ${ }^{47}$ This study was included as agomelatine was shown to be effective for the treatment of anhedonia (assessed by SHAPS total score) in patients with MDD in an 8 -week, open-label trial. ${ }^{48}$ Only patients with depressive symptoms considered nonresponsive or partially responsive to a single SSRI/SNRI treatment course of an adequate dose (approved) and duration ( $\geq 6$ weeks) were eligible for this study. Other key eligibility criteria were duration of current major depressive episode $<12$ months, and MADRS total 
Table I Key Inclusion Criteria for the Placebo-Controlled Trials

\begin{tabular}{|c|c|c|c|c|c|}
\hline Study & Treatment Arm & $\mathbf{N}$ & $\begin{array}{l}\text { Age Range } \\
\text { (Years) }\end{array}$ & $\begin{array}{l}\text { Duration of Current } \\
\text { MDE }\end{array}$ & $\begin{array}{l}\text { MADRS Total } \\
\text { Score }\end{array}$ \\
\hline NCT00635219 (II 1984A) $)^{36}$ & $\begin{array}{l}\text { Placebo } \\
\text { Vortioxetine } 5 \mathrm{mg} / \text { day } \\
\text { Vortioxetine } 10 \mathrm{mg} / \text { day }\end{array}$ & $\begin{array}{l}145 \\
155 \\
151\end{array}$ & $18-75$ & $\geq 3$ months & $\geq 26$ \\
\hline NCT0II $40906(13267 A)^{37}$ & $\begin{array}{l}\text { Placebo } \\
\text { Vortioxetine } 15 \mathrm{mg} / \text { day } \\
\text { Vortioxetine } 10 \mathrm{mg} / \text { day }\end{array}$ & $\begin{array}{l}158 \\
149 \\
152\end{array}$ & $18-75$ & $\geq 3$ months & $\geq 26$ \\
\hline NCT00672958 $(303)^{38}$ & $\begin{array}{l}\text { Placebo } \\
\text { Vortioxetine } 5 \mathrm{mg} / \text { day }\end{array}$ & $\begin{array}{l}286 \\
292\end{array}$ & $18-75$ & $\geq 3$ months & $\geq 30$ \\
\hline NCT00672620 (304) ${ }^{39}$ & $\begin{array}{l}\text { Placebo } \\
\text { Vortioxetine } 5 \mathrm{mg} / \text { day }\end{array}$ & $\begin{array}{l}149 \\
153\end{array}$ & $18-75$ & $\geq 3$ months & $\geq 22$ \\
\hline NCT00735709 $(305)^{40}$ & $\begin{array}{l}\text { Placebo } \\
\text { Vortioxetine } 5 \mathrm{mg} / \text { day } \\
\text { Vortioxetine } 10 \mathrm{mg} / \text { day }\end{array}$ & $\begin{array}{l}139 \\
139 \\
139\end{array}$ & $18-75$ & $\geq 3$ months & $\geq 26$ \\
\hline NCTOIII53009 $(315)^{41}$ & $\begin{array}{l}\text { Placebo } \\
\text { Vortioxetine } 15 \mathrm{mg} / \text { day } \\
\text { Vortioxetine } 20 \mathrm{mg} / \text { day }\end{array}$ & $\begin{array}{l}153 \\
145 \\
147\end{array}$ & $18-75$ & $\geq 3$ months & $\geq 26$ \\
\hline NCT0II $63266(316)^{42}$ & $\begin{array}{l}\text { Placebo } \\
\text { Vortioxetine } 10 \mathrm{mg} / \text { day } \\
\text { Vortioxetine } 20 \mathrm{mg} / \text { day }\end{array}$ & $\begin{array}{l}155 \\
155 \\
148\end{array}$ & $18-75$ & $\geq 3$ months & $\geq 26$ \\
\hline NCT0II79516 $(317)^{43}$ & $\begin{array}{l}\text { Placebo } \\
\text { Vortioxetine } 10 \mathrm{mg} / \text { day } \\
\text { Vortioxetine } 15 \mathrm{mg} / \text { day }\end{array}$ & $\begin{array}{l}149 \\
143 \\
142\end{array}$ & $18-75$ & $\geq 3$ months & $\geq 26$ \\
\hline NCTOI 255787 (ССТ-002) ${ }^{44}$ & $\begin{array}{l}\text { Placebo } \\
\text { Vortioxetine } 5 \mathrm{mg} / \text { day } \\
\text { Vortioxetine } 10 \mathrm{mg} / \text { day } \\
\text { Vortioxetine } 20 \mathrm{mg} / \text { day }\end{array}$ & $\begin{array}{l}150 \\
144 \\
147 \\
149\end{array}$ & $20-64$ & $\geq 3$ months & $\geq 26$ \\
\hline NCTOI35508I (CСT-003) $)^{45}$ & $\begin{array}{l}\text { Placebo } \\
\text { Vortioxetine } 15 \mathrm{mg} / \text { day } \\
\text { Vortioxetine } 20 \mathrm{mg} / \text { day }\end{array}$ & $\begin{array}{l}124 \\
119 \\
122\end{array}$ & $20-75$ & $\geq 3$ months & $\geq 26$ \\
\hline NCT023898I6 (ССT-004) $)^{46}$ & $\begin{array}{l}\text { Placebo } \\
\text { Vortioxetine } 10 \mathrm{mg} / \text { day } \\
\text { Vortioxetine } 20 \mathrm{mg} / \text { day }\end{array}$ & $\begin{array}{l}161 \\
165 \\
163\end{array}$ & $20-75$ & $\geq 3$ months & $\geq 26$ \\
\hline
\end{tabular}

Abbreviations: MADRS, Montgomery-Åsberg Depression Rating Scale; MDE, major depressive episode.

score $\geq 22$ and MADRS item 1 (apparent sadness) score $\geq 3$ at screening and baseline visits. Following a screening period of 4-10 days, eligible patients were switched from their previous treatment for 12 weeks of double-blind treatment with either vortioxetine or agomelatine. During the first 4 weeks of the study, vortioxetine and agomelatine doses were individually adjusted according to the investigator's clinical judgment. After week 4, doses were fixed.
All studies included in this analysis were conducted in accordance with the Declaration of Helsinki and Good Clinical Practice guidelines and were approved by the necessary research ethics committees. Patients provided written informed consent for participation. Further ethical approval was not required for this pooled analysis, as it used data from studies that have already been published. 


\section{Outcome Measures}

Overall depression severity was assessed by the MADRS total score. ${ }^{49}$ Anhedonia was assessed by means of the MADRS 5-item anhedonia subscale score, which was based on the following MADRS items: 1 (apparent sadness), 2 (reported sadness), 6 (concentration difficulties), 7 (lassitude), and 8 (inability to feel). ${ }^{6}$ Functional impairment was assessed using the SDS. ${ }^{50,51}$ This brief selfreport measure assesses three functional domains (work/ school, social life/leisure, and family life/home responsibility) over the previous 7 days. Patients rate the severity of impairment for each domain on a scale of $0-10$, with higher scores indicating greater impairment. Scores from the individual domains are combined to generate the SDS total score, which ranges from 0 (unimpaired) to 30 (highly impaired). For all these scales, higher scores indicate greater impairment.

\section{Statistical Analysis}

The population analyzed was the full analysis set comprising all treated patients with at least one valid postbaseline efficacy assessment. For all studies, mean changes from baseline to study endpoint in MADRS total score, MADRS anhedonia subscale score, SDS total score, and SDS social-functioning score were analyzed by a mixed model for repeated measures, with freely varying mean and covariance structure and adjusting for baseline levels and site. A standard, aggregateddata, random-effects statistical meta-analysis methodology was applied based on the estimates obtained in the individual placebo-controlled studies. For the placebocontrolled studies, data were analyzed by vortioxetine dose $(5,10,15$, or $20 \mathrm{mg})$.

The relationship between potential effects on anhedonia and functioning was investigated further using a path analysis approach. The direct effect of vortioxetine on functioning was separated from the total effect by adjusting for the change in anhedonia in an analysis of covariance model. The direct effect was expressed as a percentage of the originally obtained total effect (ie $100 \times$ direct effect/total effect).

Nominal significance levels were set at $P<0.05$, although the individual studies involved separate multiplicity adjustments and test strategies. Analyses were conducted using SAS statistical software, version 9.4 (SAS Institute Inc., Cary, NC, USA).

\section{Results \\ Study Population}

Patient demographics and clinical characteristics at baseline for the included studies are shown in Table 2. In the placebo-controlled studies, 3219 patients were treated with vortioxetine and 1769 received placebo. In the activecomparator study, 253 patients received vortioxetine and 242 received agomelatine. Demographic and treatment characteristics were generally similar across treatment groups.

\section{Placebo-Controlled Studies}

Significant dose-dependent improvements in overall depressive symptoms, anhedonia, and measures of functioning were seen in vortioxetine-treated patients compared with those who received placebo. The mean difference in change from baseline versus placebo for MADRS total score was -1.71 for vortioxetine $5 \mathrm{mg}(P=0.006),-2.49$ for vortioxetine $10 \mathrm{mg}(P<0.001),-2.60$ for vortioxetine $15 \mathrm{mg}$ $(P=0.105)$, and -3.79 for vortioxetine $20 \mathrm{mg}(P<0.001)$ (Figure 1A). The mean difference versus placebo for the MADRS anhedonia subscale score was -0.97 for vortioxetine $5 \mathrm{mg}(P=0.009),-1.37$ for vortioxetine $10 \mathrm{mg}$ $(P<0.001),-1.68$ for vortioxetine $15 \mathrm{mg}(P=0.086)$, and -2.24 for vortioxetine $20 \mathrm{mg}(P<0.001)$ (Figure 1B). The mean difference versus placebo for SDS total score was -0.68 for vortioxetine $5 \mathrm{mg}(P=0.104),-1.49$ for vortioxetine $10 \mathrm{mg}(P<0.001),-0.91$ for vortioxetine $15 \mathrm{mg}$ $(P=0.452)$, and -1.73 for vortioxetine $20 \mathrm{mg}(P<0.001)$ (Figure 1C). The mean difference versus placebo for SDS social-functioning score was -0.26 for vortioxetine $5 \mathrm{mg}$ $(P=0.056),-0.53$ for vortioxetine $10 \mathrm{mg}(P<0.001)$, -0.21 for vortioxetine $15 \mathrm{mg}(P=0.602)$, and -0.68 for vortioxetine $20 \mathrm{mg}(P=0.002)$ (Figure 1D).

Results of the path analysis for the placebo-controlled studies showed that the effect of vortioxetine on functioning was almost entirely driven by the effect of treatment on anhedonia (Figure 2).

\section{Comparison with Agomelatine}

Statistically significant differences between vortioxetine (flexible dose 10-20 mg/day) and agomelatine were seen for change from baseline in MADRS total score, MADRS anhedonia subscale score, SDS total score, and SDS social-functioning score from week 4 onwards (Table 3). At week 12, the mean difference for vortioxetine versus agomelatine was -2.03 for MADRS total score 
Table 2 Demographics and Baseline Clinical Characteristics

\begin{tabular}{|c|c|c|c|c|c|c|c|}
\hline & \multicolumn{5}{|c|}{ Placebo-Controlled Studies $(\mathrm{N}=\mathrm{I} \mathrm{I})$} & \multicolumn{2}{|c|}{ Active-Comparator Study } \\
\hline & Placebo & $\begin{array}{l}\text { Vortioxetine } \\
5 \mathrm{mg} / \text { day }\end{array}$ & $\begin{array}{l}\text { Vortioxetine } \\
10 \mathrm{mg} / \text { day }\end{array}$ & $\begin{array}{l}\text { Vortioxetine } \\
15 \mathrm{mg} / \text { day }\end{array}$ & $\begin{array}{l}\text { Vortioxetine } \\
20 \mathrm{mg} / \text { day }\end{array}$ & $\begin{array}{l}\text { Vortioxetine } \\
10-20 \mathrm{mg} / \text { day }\end{array}$ & $\begin{array}{l}\text { Agomelatine } \\
25-50 \mathrm{mg} / \mathrm{day}\end{array}$ \\
\hline No. of patients & 1769 & 1002 & 1022 & 436 & 759 & 253 & 242 \\
\hline Sex, \% female & 61.5 & 62.4 & 61.0 & 68.8 & 63.1 & 77.1 & 72.3 \\
\hline Age, years & $43 \pm 12$ & $43 \pm 13$ & $44 \pm 12$ & $45 \pm 14$ & $43 \pm 13$ & $47 \pm 12$ & $46 \pm 12$ \\
\hline $\begin{array}{l}\text { MADRS total } \\
\text { score }\end{array}$ & $31.9 \pm 4.1$ & $32.2 \pm 4.2$ & $32.1 \pm 4.3$ & $32.5 \pm 4.1$ & $31.6 \pm 3.9$ & $29.1 \pm 4.4$ & $28.7 \pm 4.0$ \\
\hline $\begin{array}{l}\text { MADRS anhedonia } \\
\text { score }\end{array}$ & $19.0 \pm 2.5$ & $19.1 \pm 2.5$ & $18.9 \pm 2.5$ & $19.3 \pm 2.3$ & $18.8 \pm 2.3$ & $17.3 \pm 2.4$ & $17.1 \pm 2.3$ \\
\hline SDS total score & $18.3 \pm 6.3$ & $18.5 \pm 6.5$ & $17.9 \pm 6.4$ & $20.2 \pm 5.6$ & $18.2 \pm 5.9$ & $19.2 \pm 5.3$ & $19.3 \pm 5.3$ \\
\hline $\begin{array}{l}\text { SDS social- } \\
\text { functioning score }\end{array}$ & $6.5 \pm 2.3$ & $6.4 \pm 2.4$ & $6.3 \pm 2.3$ & $7.1 \pm 2.1$ & $6.3 \pm 2.2$ & $6.4 \pm 2.1$ & $6.5 \pm 2.0$ \\
\hline
\end{tabular}

Note: All values are mean \pm standard deviation unless otherwise indicated.

Abbreviations: MADRS, Montgomery-Åsberg Depression Rating Scale; SDS, Sheehan Disability Scale.

$(P=0.005),-1.02$ for MADRS anhedonia subscale score $(P=0.027),-1.75$ for SDS total score $(P=0.021)$, and -0.55 for SDS social-functioning score $(P=0.015)$.

The path analysis for this study estimated the direct effect of treatment to account for $64 \%$ of the total effect on functioning (Figure 3).

\section{Discussion}

Results of this analysis show that vortioxetine is effective for the treatment of anhedonia in patients with MDD. This finding is in keeping with the results of other meta- and network analyses showing vortioxetine to be efficacious in reducing overall depressive symptom severity in patients with MDD. ${ }^{52-55}$ Significant dose-dependent effects were seen on measures of anhedonia and functioning compared with placebo over the range of 5-20 mg/day, with higher doses $(10,15$, and $20 \mathrm{mg})$ shown to be associated with greater clinical response. Compared with agomelatine, which has previously been shown to be effective for the treatment of anhedonia in patients with MDD, ${ }^{48}$ vortioxetine 10-20 mg also demonstrated a superior effect on anhedonia and functioning.

The therapeutic dose range for vortioxetine is $5-20 \mathrm{mg} /$ day; the recommended starting dose is $10 \mathrm{mg}$ once daily, which can be adjusted based on clinical response. ${ }^{56}$ Results of this analysis confirm the dose-response relationship for vortioxetine on both the MADRS total and MADRS anhedonia subscale scores, as well as on measures of patient functioning. In line with the World Federation of Societies of Biological Psychiatry guidelines, ${ }^{57}$ it is important to assess clinical response to antidepressant therapy early in the course of treatment (ie about 2 weeks after treatment initiation) to allow for any necessary dose adjustment to optimize response. ${ }^{58}$

For the placebo-controlled studies, path analysis suggested that the effect of vortioxetine on functioning was mostly driven by the improvement in MADRS anhedonia factors. This suggests a potential mediation effect for anhedonia on other outcomes in patients with MDD. However, for the active-comparator study, results of the path analysis implied some direct effect of factors other than anhedonia. It is important to note that there was no worsening of anhedonia and no suggestion of emotional blunting in vortioxetine-treated patients. In contrast, worsening of anhedonia and emotional blunting have been reported in patients with MDD treated with other antidepressants. $^{8-11}$

The relationship between depressive symptoms and functioning in MDD is complex. Early in the disease course, the correlation between presence, type, and severity of symptoms and functioning appears to be more consistent and can be replicated. However, in treated patients with depression, the relationship between depressive symptoms and functioning appears less consistent, suggesting that particular types or domains of depressive symptoms or other unmeasured factors are more relevant to and explain functioning. ${ }^{59,60}$ Results from the Sequenced Treatment Alternatives to Relieve Depression (STAR*D) study showed individual symptoms of depression to have differential effects in terms of functional impairment in outpatients with depression receiving their first antidepressant treatment, with variance ranging from 
A MADRS total score

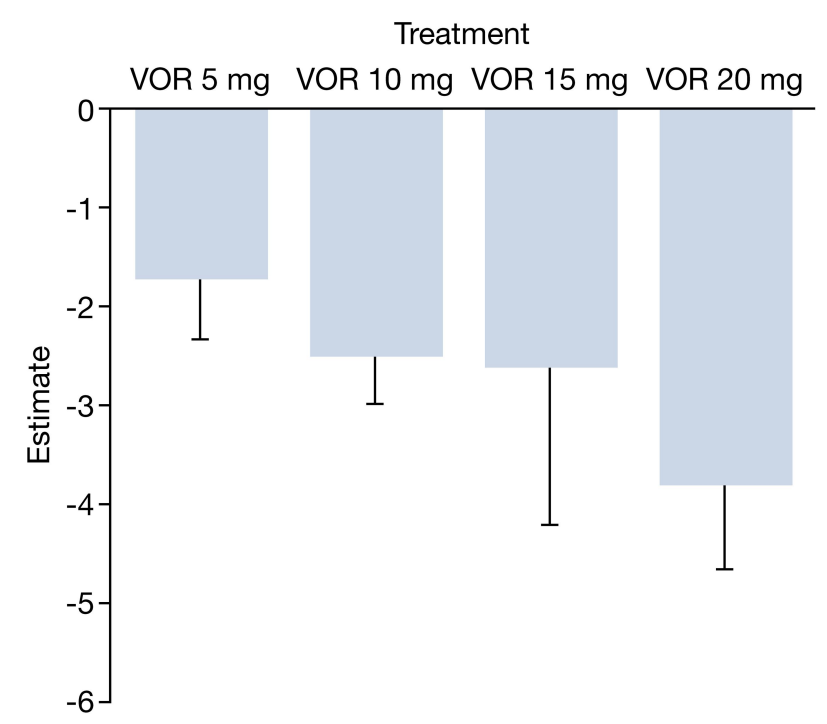

C SDS total score

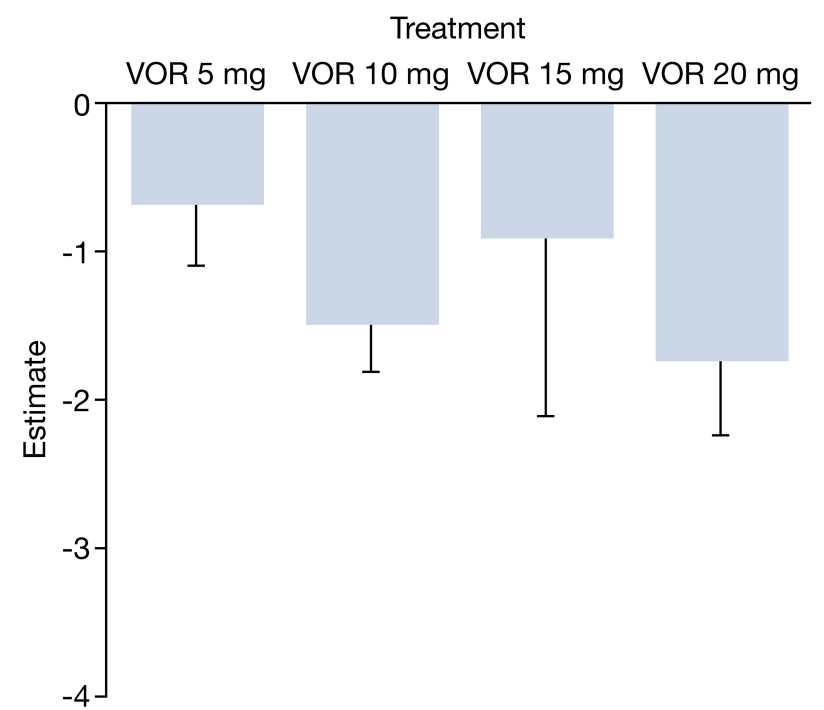

B MADRS anhedonia subscale score

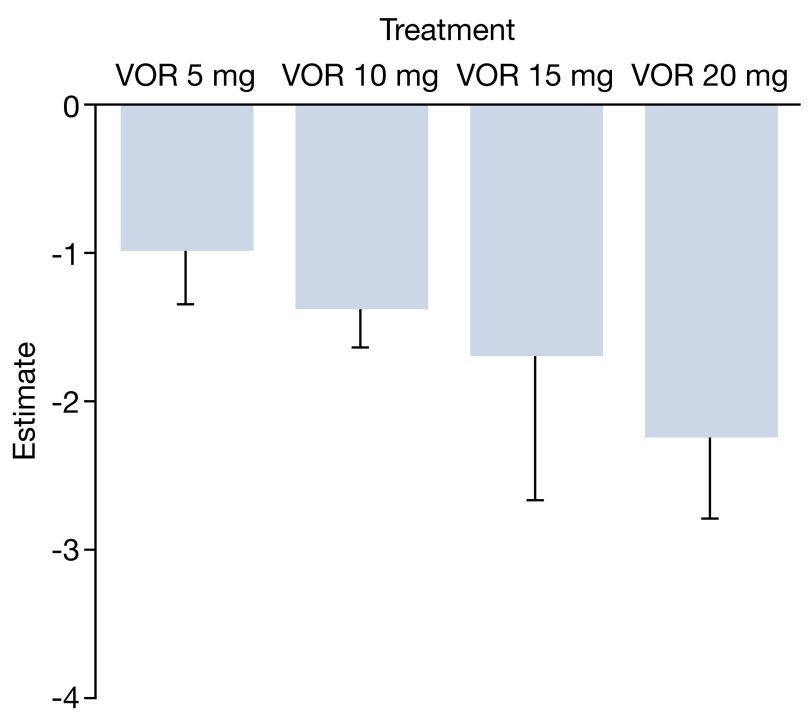

D SDS social-functioning score

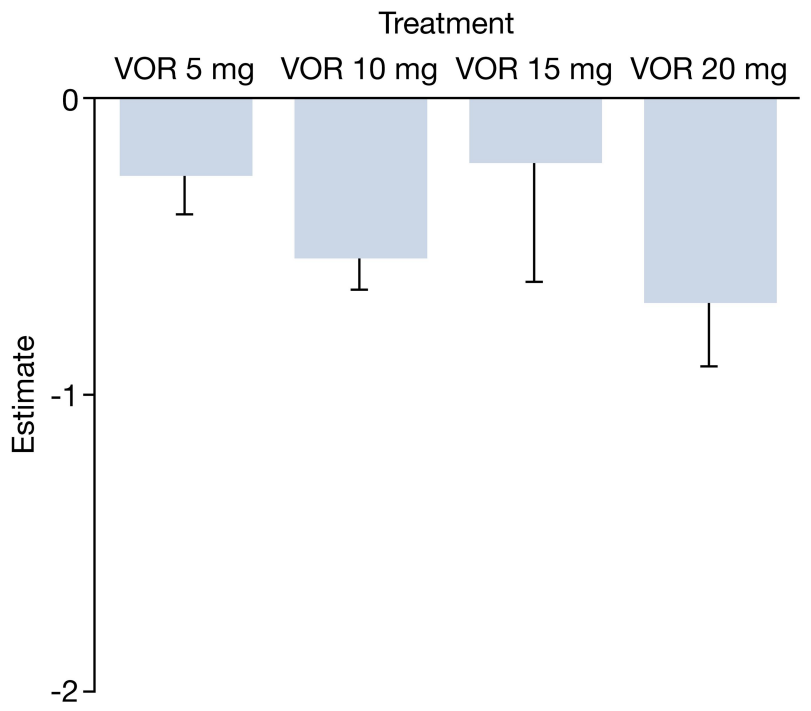

Figure I Mean difference in change from baseline for vortioxetine versus placebo for (A) MADRS total score, (B) MADRS anhedonia subscale score, (C) SDS total score, and (D) SDS social-functioning score (full analysis set; mixed-model repeated-measures analysis).

Abbreviations: MADRS, Montgomery-Åsberg Depression Rating Scale; SDS, Sheehan Disability Scale; VOR, vortioxetine.

$20.7 \%$ for sad mood and $16.5 \%$ for concentration, to $0.7 \%$ for hypersomnia. ${ }^{59}$ In patients with remitted MDD in $\mathrm{STAR}^{*} \mathrm{D}$, principal-component analysis showed that relapse was more likely in patients with decreased selfrated quality of life and functioning at baseline than those without. $^{61}$ The observation that certain symptoms or domains associated with depression are more relevant than others to functioning appears to be substantiated by the results of the current study, in which improvement in anhedonia appeared to mediate treatment effects on functioning in patients with MDD.

Anhedonia encompasses multiple discrete and overlapping phenotypic dimensions as well as neurobiological substrates; ${ }^{2}$ for example, it may include aspects of reward valuation, reward response, and reward learning. Both reward valuation and response overlap with the typology "anticipatory" as well as "consummatory hedonism". 62 Reward learning involves aspects of reward salience and 


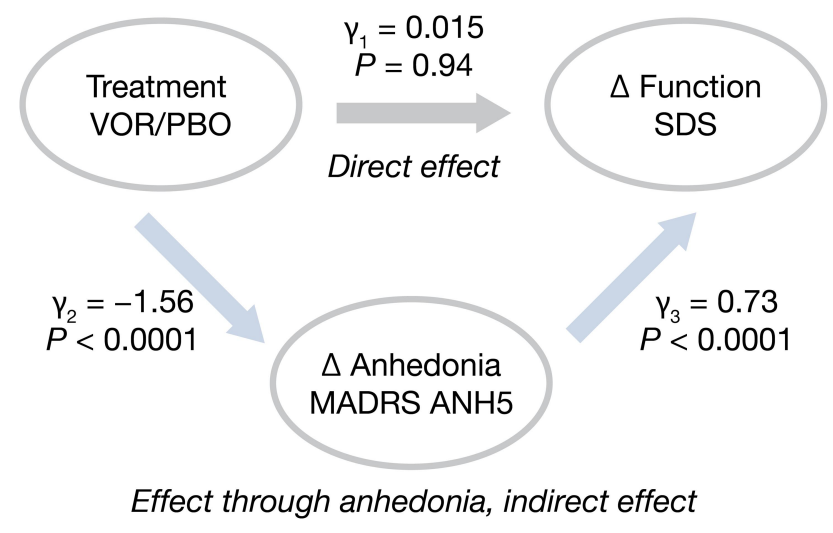

Figure 2 Path analysis to estimate direct effects of treatment with vortioxetine on functioning: placebo-controlled studies.

Notes: Indirect effect $=-1.56 * 0.73=-1.14 ;$ total effect $=-1.14+(0.015)=-1.13$ $\approx-1.14$; percent direct effect $=0.15 /-1.14 \approx 0 \%$.

Abbreviations: ANH5, 5-item anhedonia subscale; MADRS, Montgomery-Åsberg Depression Rating Scale; PBO, placebo; SDS, Sheehan Disability Scale; VOR, vortioxetine; $\gamma$, estimates of effects and associations obtained from the analysis of covariance models.

is also considered to be abnormal in many individuals with MDD. When evaluating neurochemical systems as a "unit of analysis", dopaminergic functioning is more closely linked to reward valuation, with opioid and cannabinoidergic systems implicated in reward response. Hierarchically, neural circuits/networks subserving cognitive emotional processing are also implicated in all aspects of reward phenomenology. ${ }^{63}$

A number of neurobiological mechanisms may account for the observed beneficial effects of vortioxetine on anhedonia. These include its well-documented effects on 5- $\mathrm{HT}_{3}$ receptors, ${ }^{27-29}$ as well as indirect downstream effects on dopamine ${ }^{64,65}$ and glutamate neurotransmission. ${ }^{66}$ Disturbed dopaminergic transmission has been shown to have a higher correlation with anhedonia severity than with other symptoms of depression, ${ }^{67}$ and it has been hypothesized that the pro-cognitive effects of vortioxetine may be mediated via $5-\mathrm{HT}_{3}$ heteroreceptors on GABAergic interneurons, thereby increasing glutamatergic activation. ${ }^{66}$ Glutamate targeting appears to be a promising approach for the treatment of anhedonia in MDD. ${ }^{68}$ Indeed, the reported beneficial effects of ketamine on anhedonia appear to be mediated through localized effects on glutamate in the nucleus accumbens. ${ }^{69,70}$ The potential antidepressant effects of lumateperone, an atypical antipsychotic recently approved in the USA for the treatment of schizophrenia in adults and in development for bipolar disorder and MDD, also appear to be mediated by glutaminergic mechanisms, albeit indirectly through dopamine D1 receptors. ${ }^{71}$

In patients with remitted depression and healthy controls, vortioxetine has also been shown to have direct effects on the efficiency of neural circuits supporting cognitive function, for example, in the hippocampus and dorsolateral prefrontal cortex. ${ }^{72}$ These upstream circuit effects may at least in part account for the observed improvement in anhedonia in vortioxetine-treated patients. Vortioxetine may additionally have beneficial effects on inflammatory systems. ${ }^{73}$ Inflammation is known to amplify anhedonia, and drugs that affect inflammation appear to have antianhedonic properties. ${ }^{33,74}$

The observed differences between vortioxetine and agomelatine in this analysis may at least in part be due to differences in their mechanism of action. Agomelatine is a melatoninergic $\mathrm{MT}_{1}$ and $\mathrm{MT}_{2}$ receptor agonist (modulating circadian rhythms) and a selective $5-\mathrm{HT}_{2 \mathrm{C}}$ receptor antagonist (increasing serotonin and dopamine levels in the frontal cortex). ${ }^{75}$ Studies investigating the effects of agomelatine on anhedonia have only utilized the SHAPS scale, which mostly measures consummatory pleasure. ${ }^{48,76,77}$ In contrast,

Table 3 Analysis of Difference in Change from Baseline in MADRS Total Score, MADRS Anhedonia Subscale Score, SDS Total Score, and SDS Social-Functioning Score for Vortioxetine $10-20 \mathrm{mg} /$ day versus Agomelatine $25-50 \mathrm{mg} /$ day (Full Analysis Set; Mixed-Model Repeated-Measures Analysis)

\begin{tabular}{|l|l|l|l|l|l|l|l|l|}
\hline \multirow{2}{*}{ Timepoint (Week) } & \multicolumn{2}{l|}{$\begin{array}{l}\text { MADRS Total } \\
\text { Score }\end{array}$} & \multicolumn{2}{l|}{$\begin{array}{l}\text { MADRS Anhedonia Subscale } \\
\text { Score }\end{array}$} & \multicolumn{2}{l|}{ SDS Total Score } & \multicolumn{2}{l|}{$\begin{array}{l}\text { SDS Social-Functioning } \\
\text { Score }\end{array}$} \\
\cline { 2 - 8 } & Diff (SE) & $\boldsymbol{P}$ & Diff (SE) & $\boldsymbol{P}$ & Diff (SE) & $\boldsymbol{P}$ & Diff (SE) & $\boldsymbol{P}$ \\
\hline 1 & $-0.56(0.34)$ & 0.098 & $-0.22(0.20)$ & 0.286 & & & \\
2 & $-0.15(0.47)$ & 0.758 & $0.01(0.28)$ & 0.980 & & & \\
3 & $-0.86(0.56)$ & 0.126 & $-0.28(0.34)$ & 0.410 & & & \\
4 & $-1.99(0.63)$ & 0.002 & $-1.13(0.39)$ & 0.005 & $-2.50(0.67)$ & $<0.001$ & $-0.62(0.21)$ \\
8 & $-2.16(0.69)$ & 0.002 & $-1.05(0.42)$ & 0.014 & $-2.22(0.72)$ & 0.002 & $-0.66(0.23)$ & 0.003 \\
12 & $-2.03(0.72)$ & 0.005 & $-1.02(0.46)$ & 0.027 & $-1.75(0.75)$ & 0.021 & $-0.55(0.22)$ & 0.004 \\
\hline
\end{tabular}

Abbreviations: Diff, difference (vortioxetine - agomelatine); MADRS, Montgomery-Åsberg Depression Rating Scale; SDS, Sheehan Disability Scale; SE, standard error. 


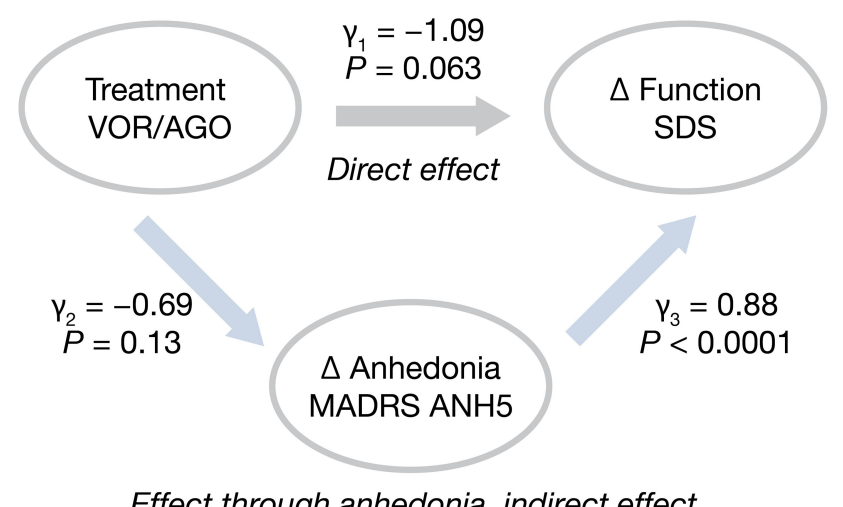

Effect through anhedonia, indirect effect

Figure 3 Path analysis to estimate direct effects of treatment with vortioxetine on functioning: active-comparator study.

Notes: Indirect effect $=-0.69 * 0.88=-0.61$; total effect $=-0.61+(-1.09)=-1.70$; percent direct effect $=-1.09 / 1.70=64 \%$.

Abbreviations: AGO, agomelatine; ANH5, 5-item anhedonia subscale; MADRS, Montgomery-Åsberg Depression Rating Scale; SDS, Sheehan Disability Scale; VOR, vortioxetine; $\gamma$, estimates of effects and associations obtained from the analysis of covariance models.

vortioxetine has been shown to have effects on two different measures of anhedonia (the SHAPS scale and the MADRS anhedonia subscale), with improvements in anhedonia in vortioxetine-treated patients shown to directly mediate the association between improvements in overall depressive symptom severity and functioning. ${ }^{6}$ Vortioxetine has also been separately studied on two disparate aspects of anhedonia in patients with MDD: anticipation (assessed by the Effort Expenditure Reward Task [EEfRT]), ${ }^{78}$ and consummatory pleasure. ${ }^{6}$ To our knowledge, similar mediation analyses and motivational/ effort tests have not been undertaken for agomelatine.

This analysis has some limitations. First, this was a post hoc analysis, and evaluating the effect of vortioxetine on anhedonia was not the primary aim of the placebocontrolled studies included. Second, only short-term studies were available for inclusion, precluding assessment of long-term treatment effects. Nevertheless, the acute effect of antidepressant treatment on anhedonia is still a relevant outcome for practicing psychiatrists. ${ }^{79}$ Third, only the MADRS anhedonia subscale was used as a measure of anhedonia in this analysis and it may also have been of scientific interest to investigate effects on anhedonia using scales specifically developed for this symptom (such as the SHAPS, the Fawcett-Clark Pleasure Capacity Scale, or the Chapman Scales for Physical and Social Anhedonia). ${ }^{80-82}$ However, unlike the MADRS, these scales are not routinely used in randomized controlled trials of antidepressant therapy. Finally, the general limitation of randomized controlled trials in MDD apply to our findings, particularly that study participants may not be fully representative of patients with MDD in routine practice settings. Clinical presentation of MDD is known to be highly heterogeneous and its differential diagnosis may be influenced by multiple factors that alter over time. ${ }^{83}$ In particular, many patients with MDD have other psychiatric illnesses; ${ }^{84}$ however, patients with psychiatric comorbidities were excluded from the studies included in this pooled analysis. Nevertheless, our results replicate earlier findings showing a significant effect of vortioxetine on anhedonia in an open-label study, ${ }^{6}$ and extend these to a much larger patient population derived from randomized controlled clinical trials versus placebo and an active comparator (agomelatine).

\section{Conclusion}

Vortioxetine showed significant short-term efficacy against anhedonia in this large population of patients with MDD. Improvements in functioning conferred by vortioxetine appeared to be mostly driven by the effect of treatment on MADRS anhedonia factors.

\section{Abbreviations}

EEfRT, Effort Expenditure Reward Task; 5-HT, serotonin; MADRS, Montgomery-Åsberg Depression Rating Scale; MDD, Major depressive disorder; SDS, Sheehan Disability Scale; SHAPS, Snaith-Hamilton Pleasure Scale; SNRI, Serotonin-noradrenaline reuptake inhibitor; SSRI, selective serotonin reuptake inhibitor; STAR*D, Sequenced Treatment Alternatives to Relieve Depression.

\section{Data Sharing Statement}

The majority of data accessed from the trials are freely available; the corresponding author may be contacted for further data sharing.

\section{Acknowledgments}

Data for this study are from clinical studies sponsored by H. Lundbeck A/S Valby, Denmark, and Takeda Pharmaceuticals Inc., Deerfield, Illinois. Medical writing support was provided by Jennifer Coward of Anthemis Consulting Ltd, funded by $\mathrm{H}$. Lundbeck A/S.

\section{Author Contributions}

All authors made substantial contributions to conception and design, acquisition of data, or analysis and interpretation of data; took part in drafting the article or revising it critically for important intellectual content; agreed to submit to the current journal; gave final approval of the 
version to be published; and agree to be accountable for all aspects of the work.

\section{Disclosure}

$\mathrm{RM}$ is a consultant for, and/or has received research support from Lundbeck, Janssen, Shire, Purdue, Pfizer, Otsuka, Allergan, Takeda, Neurocrine, Sunovion, Eisai, Minerva, Intra-Cellular, AbbVie, Stanley Medical Research Institute, and CIHR/GACD/Chinese National Natural Research Foundation. RM is the CEO of AltMed. RM has not received financial support from $\mathrm{H}$. Lundbeck A/S or other sources for the research presented in this manuscript. HL and MCC are employees of $\mathrm{H}$. Lundbeck A/S. The authors report no other conflicts of interest in this work.

\section{References}

1. Rizvi SJ, Pizzagalli DA, Sproule BA, Kennedy SH. Assessing anhedonia in depression: potentials and pitfalls. Neurosci Biobehav Rev 2016;65:21-35. doi:10.1016/j.neubiorev.2016.03.004

2. De Fruyt J, Sabbe B, Demyttenaere K. Anhedonia in depressive disorder: a narrative review. Psychopathology. 2020;53(5-6):274 281. doi: $10.1159 / 000508773$

3. American Psychiatric Association. Diagnostic and Statistical Manual of Mental Disorders. 5th ed. Washington, DC: American Psychiatric Association; 2013.

4. Horan WP, Kring AM, Blanchard JJ. Anhedonia in schizophrenia: a review of assessment strategies. Schizophr Bull. 2006;32(2):259-273. doi:10.1093/schbul/sbj009

5. Franken IH, Rassin E, Muris P. The assessment of anhedonia in clinical and non-clinical populations: further validation of the Snaith-Hamilton pleasure scale (SHAPS). J Affect Disord. 2007;99 (1-3):83-89. doi:10.1016/j.jad.2006.08.020

6. Cao B, Park C, Subramaniapillai M, et al. The efficacy of vortioxetine on anhedonia in patients with major depressive disorder. Front Psychiatry. 2019;10:17. doi:10.3389/fpsyt.2019.00017

7. Nierenberg AA. Residual symptoms in depression: prevalence and impact. J Clin Psychiatry. 2015;76(11):e1480. doi:10.4088/ JCP.13097TX1C

8. Sansone RA, Sansone LA. SSRI-induced indifference. Psychiatry (Edgmont). 2010;7:14-18.

9. Price J, Cole V, Goodwin GM. Emotional side-effects of selective serotonin reuptake inhibitors: qualitative study. $\mathrm{Br} J$ Psychiatry. 2009;195(3):211-217. doi:10.1192/bjp.bp.108.051110

10. Read J, Cartwright C, Gibson K. Adverse emotional and interpersonal effects reported by 1829 New Zealanders while taking antidepressants. Psychiatry Res. 2014;216(1):67-73. doi:10.1016/j. psychres.2014.01.042

11. Goodwin GM, Price J, De Bodinat C, Laredo J. Emotional blunting with antidepressant treatments: a survey among depressed patients. $J$ Affect Disord. 2017;221:31-35. doi:10.1016/j.jad.2017.05.048

12. Buckner JD, Joiner TE, Pettit JW, Lewinsohn PM, Schmidt NB. Implications of the DSM's emphasis on sadness and anhedonia in major depressive disorder. Psychiatry Res. 2008;159(1-2):25-30. doi:10.1016/j.psychres.2007.05.010

13. Vinckier F, Gourion D, Mouchabac S. Anhedonia predicts poor psychosocial functioning: results from a large cohort of patients treated for major depressive disorder by general practitioners. Eur Psychiatry. 2017;44:1-8. doi:10.1016/j.eurpsy.2017.02.485
14. McMakin DL, Olino TM, Porta G, et al. Anhedonia predicts poorer recovery among youth with selective serotonin reuptake inhibitor treatment-resistant depression. $J$ Am Acad Child Adolesc Psychiatry. 2012;51(4):404-411. doi:10.1016/j.jaac.2012.01.011

15. Uher R, Perlis R, Henigsberg N, et al. Depression symptom dimensions as predictors of antidepressant treatment outcome: replicable evidence for interest-activity symptoms. Psychol Med. 2012;42 (5):967-980. doi:10.1017/S0033291711001905

16. Vrieze E, Demyttenaere K, Bruffaerts R, et al. Dimensions in major depressive disorder and their relevance for treatment outcome. $J$ Affect Disord. 2014;155:35-41. doi:10.1016/j.jad.2013.10.020

17. Khazanov GK, Xu C, Dunn BD, Cohen ZD, DeRubeis R, Hollon SD. Distress and anhedonia as predictors of depression treatment outcome: a secondary analysis of a randomized clinical trial. Behav Res Ther. 2020;125:103507. doi:10.1016/j.brat.2019.103507

18. Yee A, Chin SC, Hashim AH, et al. Anhedonia in depressed patients on treatment with selective serotonin reuptake inhibitor anti-depressant—a two-centered study in Malaysia. Int J Psychiatry Clin Pract. 2015;19(3):182-187. doi:10.3109/13651501.2015.1031139

19. Winer ES, Nadorff MR, Ellis TE, Allen JG, Herrera S, Salem T. Anhedonia predicts suicidal ideation in a large psychiatric inpatient sample. Psychiatry Res. 2014;218(1-2):124-128. doi:10.1016/j. psychres.2014.04.016

20. Winer ES, Drapeau CW, Veilleux JC, Nadorff MR. The association between anhedonia, suicidal ideation, and suicide attempts in a large student sample. Arch Suicide Res. 2016;20(2):265-272. doi:10.1080/ 13811118.2015.1025119

21. Ballard ED, Wills K, Lally N, et al. Anhedonia as a clinical correlate of suicidal thoughts in clinical ketamine trials. J Affect Disord. 2017;218:195-200. doi:10.1016/j.jad.2017.04.057

22. Ducasse D, Loas G, Dassa D, et al. Anhedonia is associated with suicidal ideation independently of depression: a meta-analysis. Depress Anxiety. 2018;35(5):382-392. doi:10.1002/da.22709

23. Pan Z, Rosenblat JD, Swardfager W, McIntyre RS. Role of proinflammatory cytokines in dopaminergic system disturbances, implications for anhedonic features of MDD. Curr Pharm Des. 2017;23 (14):2065-2072. doi:10.2174/1381612823666170111144340

24. Höflich A, Michenthaler P, Kasper S, Lanzenberger R. Circuit mechanisms of reward, anhedonia, and depression. Int $J$ Neuropsychopharmacol. 2019;22(2):105-118. doi:10.1093/ijnp/pyy081

25. Nestler EJ, Carlezon WA Jr. The mesolimbic dopamine reward circuit in depression. Biol Psychiatry. 2006;59(12):1151-1159. doi:10.1016/ j.biopsych.2005.09.018

26. Belujon P, Grace AA. Dopamine system dysregulation in major depressive disorders. Int $J$ Neuropsychopharmacol. 2017;20 (12):1036-1046. doi:10.1093/ijnp/pyx056

27. Sanchez C, Asin KE, Artigas F. Vortioxetine, a novel antidepressant with multimodal activity: review of preclinical and clinical data. Pharmacol Ther. 2015;145:43-57. doi:10.1016/j.pharmthera.201 4.07.001

28. McIntyre RS. The role of new antidepressants in clinical practice in Canada: a brief review of vortioxetine, levomilnacipran ER, and vilazodone. Neuropsychiatr Dis Treat. 2017;13:2913-2919. doi:10.2147/NDT.S150589

29. Gonda X, Sharma SR, Tarazi FI. Vortioxetine: a novel antidepressant for the treatment of major depressive disorder. Expert Opin Drug Discov. 2019;14(1):81-89. doi:10.1080/17460441.2019.1546691

30. Lu Y, C S H, McIntyre RS, Wang W, Ho RC. Effects of vortioxetine and fluoxetine on the level of brain derived neurotrophic factors (BDNF) in the hippocampus of chronic unpredictable mild stressinduced depressive rats. Brain Res Bull. 2018;142:1-7. doi:10.1016/j. brainresbull.2018.06.007

31. McIntyre RS, Woldeyohannes HO, Soczynska JK, et al. Anhedonia and cognitive function in adults with MDD: results from the international mood disorders collaborative project. CNS Spectr. 2016;21 (5):362-366. doi:10.1017/S1092852915000747 
32. Soczynska JK, Kennedy SH, Goldstein BI, Lachowski A, Woldeyohannes HO, McIntyre RS. The effect of tumor necrosis factor antagonists on mood and mental health-associated quality of life: novel hypothesis-driven treatments for bipolar depression? Neurotoxicology. 2009;30(4):497-521. doi:10.1038/mp.2017.104

33. Lee Y, Subramaniapillai M, Brietzke E, et al. Anti-cytokine agents for anhedonia: targeting inflammation and the immune system to treat dimensional disturbances in depression. Ther Adv Psychopharmacol. 2018;8(12):337-348. doi:10.1177/2045125318791944

34. McIntyre RS, Harrison J, Loft H, Jacobson W, Olsen CK. The effects of vortioxetine on cognitive function in patients with major depressive disorder: a meta-analysis of three randomized controlled trials. Int $J$ Neuropsychopharmacol. 2016;19(10):pyw055. doi:10.1093/ijnp/pyw055

35. American Psychiatric Association. Diagnostic and Statistical Manual of Mental Disorders. 4th ed. Washington, DC: American Psychiatric Association; 2000.

36. Baldwin DS, Loft H, Dragheim M. A randomised, double-blind, placebo controlled, duloxetine-referenced, fixed-dose study of three dosages of Lu AA21004 in acute treatment of major depressive disorder (MDD). Eur Neuropsychopharmacol. 2012;22(7):482-491. doi:10.1016/j.euroneuro.2011.11.008

37. Boulenger JP, Loft H, Olsen CK. Efficacy and safety of vortioxetine (Lu AA21004), 15 and $20 \mathrm{mg} /$ day: a randomized, double-blind, placebo-controlled, duloxetine-referenced study in the acute treatment of adult patients with major depressive disorder. Int Clin Psychopharmacol. 2014;29 (3):138-149. doi:10.1097/YIC.0000000000000018

38. Jain R, Mahableshwarkar AR, Jacobsen PL, Chen Y, Thase ME. A randomized, double-blind, placebo-controlled 6-wk trial of the efficacy and tolerability of $5 \mathrm{mg}$ vortioxetine in adults with major depressive disorder. Int J Neuropsychopharmacol. 2013;16(2):313321. doi:10.1017/S1461145712000727

39. Mahableshwarkar AR, Jacobsen PL, Chen Y. A randomized, doubleblind trial of $2.5 \mathrm{mg}$ and $5 \mathrm{mg}$ vortioxetine (Lu AA21004) versus placebo for 8 weeks in adults with major depressive disorder. Curr Med Res Opin. 2013;29(3):217-226. doi:10.1185/03007995.201 2.761600

40. Henigsberg N, Mahableshwarkar A, Jacobsen P, Chen Y, Thase ME. A randomized, double-blind, placebo-controlled 8-week trial of the efficacy and tolerability of multiple doses of Lu AA21004 in adults with major depressive disorder. J Clin Psychiatry. 2012;73(07):953959. doi: $10.4088 / \mathrm{JCP} .11 \mathrm{~m} 07470$

41. Mahableshwarkar AR, Jacobsen PL, Chen Y, Serenko M, Trivedi MH. A randomized, double-blind, duloxetine-referenced study comparing efficacy and tolerability of 2 fixed doses of vortioxetine in the acute treatment of adults with MDD. Psychopharmacology (Berl). 2015;232(12):2061-2070. doi:10.1007/s00213-014-3839-0

42. Jacobsen PL, Mahableshwarkar AR, Serenko M, Chan S, Trivedi $\mathrm{MH}$. A randomized, double-blind, placebo-controlled study of the efficacy and safety of vortioxetine $10 \mathrm{mg}$ and $20 \mathrm{mg}$ in adults with major depressive disorder. J Clin Psychiatry. 2015;76(05):575-582. doi:10.4088/JCP.14m09335

43. Mahableshwarkar AR, Jacobsen PL, Serenko M, Chen Y, Trivedi MH. A randomized, double-blind, placebo-controlled study of the efficacy and safety of 2 doses of vortioxetine in adults with major depressive disorder. $J$ Clin Psychiatry. 2015;76(05):583-591. doi:10.4088/JCP.14m09337

44. Nishimura A, Aritomi Y, Sasai K, Kitagawa T, Mahableshwarkar AR. Randomized, double-blind, placebo-controlled 8-week trial of the efficacy, safety, and tolerability of 5,10 , and $20 \mathrm{mg}$ /day vortioxetine in adults with major depressive disorder. Psychiatry Clin Neurosci. 2018;72(2):64-72. doi:10.1111/pcn.12565

45. Inoue T, Nishimura A, Sasai K, Kitagawa T. Randomized, 8-week, double-blind, placebo-controlled trial of vortioxetine in Japanese adults with major depressive disorder, followed by a 52-week openlabel extension trial. Psychiatry Clin Neurosci. 2018;72(2):103-115. doi: $10.1111 / \mathrm{pcn} .12623$
46. Inoue T, Sasai K, Kitagawa T, Nishimura A, Inada I. Randomized, double-blind, placebo-controlled study to assess the efficacy and safety of vortioxetine in Japanese patients with major depressive disorder. Psychiatry Clin Neurosci. 2020;74(2):140-148. doi:10.1111/pen.12956

47. Montgomery SA, Nielsen RZ, Poulsen LH, Häggström L. A randomised, double-blind study in adults with major depressive disorder with an inadequate response to a single course of selective serotonin reuptake inhibitor or serotonin-noradrenaline reuptake inhibitor treatment switched to vortioxetine or agomelatine. Hum Psychopharmacol. 2014;29(5):470-482. doi:10.1002/hup.2424

48. Gargoloff PD, Corral R, Herbst L, Marquez M, Martinotti G, Gargoloff PR. Effectiveness of agomelatine on anhedonia in depressed patients: an outpatient, open-label, real-world study. Hum Psychopharmacol. 2016;31(6):412-418. doi:10.1002/hup.2557

49. Montgomery SA, Åsberg M. A new depression scale designed to be sensitive to change. $B r \quad J$ Psychiatry. 1979;134(4):382-389. doi:10.1192/bjp.134.4.382

50. Sheehan DV, Harnett-Sheehan K, Raj BA. The measurement of disability. Int Clin Psychopharmacol. 1996;11(Suppl 3):89-95. doi:10.1097/00004850-199606003-00015

51. Sheehan KH, Sheehan DV. Assessing treatment effects in clinical trials with the discan metric of the Sheehan Disability Scale. Int Clin Psychopharmacol. 2008;23(2):70-83. doi:10.1097/YIC.0b013e32 $82 \mathrm{f} 2 \mathrm{~b} 4 \mathrm{~d} 6$

52. Berhan A, Barker A. Vortioxetine in the treatment of adult patients with major depressive disorder: a meta-analysis of randomized double-blind controlled trials. BMC Psychiatry. 2014;14(1):276. doi:10.1186/s12888-014-0276-x

53. Baldwin DS, Florea I, Jacobsen PL, Zhong W, Nomikos GG. A metaanalysis of the efficacy of vortioxetine in patients with major depressive disorder (MDD) and high levels of anxiety symptoms. $J$ Affect Disord. 2016;206:140-150. doi:10.1016/j.jad.2016.07.015

54. Thase ME, Mahableshwarkar AR, Dragheim M, Loft H, Vieta E. A meta-analysis of randomized, placebo-controlled trials of vortioxetine for the treatment of major depressive disorder in adults. Eur Neuropsychopharmacol. 2016;26(6):979-993. doi:10.1016/j.euron euro.2016.03.007

55. Christensen MC, Florea I, Loft H, McIntyre RS. Efficacy of vortioxetine in patients with major depressive disorder reporting childhood or recent trauma. $J$ Affect Disord. 2020;263:258-266. doi:10.1016/j. jad.2019.11.074

56. European Medicines Agency. Brintellix (vortioxetine): summary of product characteristics; 2020. Available from: www.ema.europa.eu/ en/documents/product-information/brintellix-epar-product-informa tion_en.pdf. Accessed February 6, 2021.

57. Bauer M, Pfennig A, Severus E, Whybrow PC, Angst J, Moller HJ. World Federation of Societies of Biological Psychiatry Task Force on Unipolar Depressive Disorders. World Federation of Societies of Biological Psychiatry (WFSBP) guidelines for biological treatment of unipolar depressive disorders, part 1: update 2013 on the acute and continuation treatment of unipolar depressive disorders. World J Biol Psychiatry. 2013;14(5):334-385. doi:10.3109/15622975.2013.8 04195

58. Kudlow PA, Cha DS, McIntyre RS. Predicting treatment response in major depressive disorder: the impact of early symptomatic improvement. Can J Psychiatry. 2012;57(12):782-788. doi:10.1177/ 070674371205701211

59. Fried EI, Nesse RM. The impact of individual depressive symptoms on impairment of psychosocial functioning. PLoS One. 2014;9(2): e90311. doi:10.1371/journal.pone.0090311

60. McIntyre RS, Soczynska JZ, Woldeyohannes HO, et al. The impact of cognitive impairment on perceived workforce performance: results from the International Mood Disorders Collaborative Project. Compr Psychiatry. 2015;56:279-282. doi:10.1016/j.comppsych.2014.08.051 
61. IsHak WW, Greenberg JM, Cohen RM. Predicting relapse in major depressive disorder using patient-reported outcomes of depressive symptom severity, functioning, and quality of life in the Individual Burden of Illness Index for Depression (IBI-D). J Affect Disord. 2013;151(1):59-65. doi:10.1016/j.jad.2013.05.048

62. Sydnor VJ, Larsen B, Kohler C, et al. Diminished reward responsiveness is associated with lower reward network GluCEST: an ultrahigh field glutamate imaging study. Mol Psychiatry. 2021. doi:10.1038/s41380-020-00986-y

63. Fischer AS, Holt-Gosselin B, Fleming SL, et al. Intrinsic reward circuit connectivity profiles underlying symptom and quality of life outcomes following antidepressant medication: a report from the iSPOT-D trial. Neuropsychopharmacology. 2020. doi:10.1038/ s41386-020-00905-3

64. Mørk A, Pehrson A, Brennum LT, et al. Pharmacological effects of Lu AA21004: a novel multimodal compound for the treatment of major depressive disorder. J Pharmacol Exp Ther. 2012;340(3):666675. doi:10.1124/jpet.111.189068

65. Pehrson AL, Cremers T, Bétry C, et al. Lu AA21004, a novel multimodal antidepressant, produces regionally selective increases of multiple neurotransmitters - a rat microdialysis and electrophysiology study. Eur Neuropsychopharmacol. 2013;23(2):133-145. doi:10.1016/j.euron euro.2012.04.006

66. Pehrson AL, Pedersen CS, Tølbøl KS, Sanchez C. Vortioxetine treatment reverses subchronic PCP treatment-induced cognitive impairments: a potential role for serotonin receptor-mediated regulation of GABA neurotransmission. Front Pharmacol. 2018;9:162. doi:10.3389/fphar.2018.00162

67. Treadway MT. The neurobiology of motivational deficits in depression - an update on candidate pathomechanisms. Curr Top Behav Neurosci. 2016;27:337-355. doi:10.1007/78542015 400

68. Cao B, Zhu J, Zuckerman H, et al. Pharmacological interventions targeting anhedonia in patients with major depressive disorder: a systematic review. Prog Neuropsychopharmacol Biol Psychiatry. 2019;92:109-117. doi:10.1016/j.pnpbp.2019.01.002

69. Lally N, Nugent AC, Luckenbaugh DA, Niciu MJ, Roiser JP, Zarate CA Jr. Neural correlates of change in major depressive disorder anhedonia following open-label ketamine. J Psychopharmacol. 2015;29(5):596-607. doi:10.1177/0269881114568041

70. Abdallah CG, Jackowski A, Salas R, et al. The nucleus accumbens and ketamine treatment in major depressive disorder. Neuropsychopharmacology. 2017;42(8):1739-1746. doi:10.1038/npp.2017.49

71. Kumar B, Kuhad A, Kuhad A. Lumateperone: a new treatment approach for neuropsychiatric disorders. Drugs Today (Barc). 2018;54(12):713-719. doi:10.1358/dot.2018.54.12.2899443

72. Smith J, Browning M, Conen S. Vortioxetine reduces BOLD signal during performance of the N-back working memory task: a randomised neuroimaging trial in remitted depressed patients and healthy controls. Mol Psychiatry. 2018;23(5):1127-1133. doi:10.1038/mp.2017.104
73. Eskelund A, Li Y, Budac DP, et al. Drugs with antidepressant properties affect tryptophan metabolites differently in rodent models with depression-like behaviour. $J$ Neurochem. 2017;142(1):118-131. doi:10.1111/jnc. 14043

74. Shariq AS, Brietzke E, Rosenblat JD, Barendra V, Pan Z, McIntyre RS. Targeting cytokines in reduction of depressive symptoms: a comprehensive review. Prog Neuropsychopharmacol Biol Psychiatry. 2018;83:8691. doi:10.1016/j.pnpbp.2018.01.003

75. Guardiola-Lemaitre B, De Bodinat C, Delagrange P, Millan MJ, Munoz C, Mocaër E. Agomelatine: mechanism of action and pharmacological profile in relation to antidepressant properties. $\mathrm{Br} J$ Pharmacol. 2014;171(15):3604-3619. doi:10.1111/bph.12720

76. Martinotti G, Sepede G, Gambi F, et al. Agomelatine versus venlafaxine XR in the treatment of anhedonia in major depressive disorder. J Clin Psychopharmacol. 2012;32(4):487-491. doi:10.1097/JCP.0b $013 \mathrm{e} 31825 \mathrm{~d} 6 \mathrm{c} 25$

77. Di Giannantonio M, Montemitro C, Sepede G. Agomelatine effectiveness, tolerability, and impact on anhedonia in major depression: a pooled analysis. J Clin Psychopharmacol. 2019;39(3):288-290. doi:10.1097/JCP.0000000000001038

78. Subramaniapillai M, Mansur RB, Zuckerman H, et al. Association between cognitive function and performance on effort based decision making in patients with major depressive disorder treated with vortioxetine. Compr Psychiatry. 2019;94:152113. doi:10.1016/j.compps ych.2019.07.006

79. Rosenblat JD, Simon GE, Sachs GS, et al. Treatment effectiveness and tolerability outcomes that are most important to individuals with bipolar and unipolar depression. J Affect Disord. 2019;243:116-120. doi:10.1016/j.jad.2018.09.027

80. Snaith RP, Hamilton M, Morley S, et al. A scale for the assessment of hedonic tone: the Snaith-Hamilton pleasure scale. Br J Psychiatry. 1995;167(1):99-103. doi:10.1192/bjp.167.1.99

81. Fawcett J, Clark DC, Scheftner WA, Gibbons RD. Assessing anhedonia in psychiatric patients. Arch Gen Psychiatry. 1983;40(1):7984. doi:10.1001/archpsyc.1983.01790010081010

82. Chapman LJ, Chapman JP, Raulin ML. Scales for physical and social anhedonia. J Abnorm Psychol. 1976;85(4):374-382. doi:10.1037/ 0021-843X.85.4.374

83. Ng QX, Lim DY, Chee KT. Reimagining the spectrum of affective disorders. Bipolar Disord. 2020;22(6):638-639. doi:10.1111/bdi.12960

84. Thaipisuttikul P, Ittasakul P, Waleeprakhon P, et al. Psychiatric comorbidities in patients with major depressive disorder. Neuropsychiatr Dis Treat. 2014;10:2097-2103. doi:10.2147/NDT.S72026
Neuropsychiatric Disease and Treatment

\section{Publish your work in this journal}

Neuropsychiatric Disease and Treatment is an international, peerreviewed journal of clinical therapeutics and pharmacology focusing on concise rapid reporting of clinical or pre-clinical studies on a range of neuropsychiatric and neurological disorders. This journal is indexed on PubMed Central, the 'PsycINFO' database and CAS, an is the official journal of The International Neuropsychiatric Association (INA). The manuscript management system is completely online and includes a very quick and fair peer-review system, which is all easy to use. Visit http://www.dovepress.com/testimonials.php to read real quotes from published authors. 